\title{
Load-displacement properties of gravity type breakwater reinforced by steel pipe piles
}

\author{
Motohiro Suguro ${ }^{\mathrm{i})}$, Yoshiaki Kikuchii ${ }^{\mathrm{ii}}$, Masatsugu Kiko ${ }^{\mathrm{i})}$, Soichiro Nagasawa ${ }^{\mathrm{iii}}$ and \\ Shunsuke Moriyasu ${ }^{\text {iv) }}$ \\ i) Graduate Student, Department of Civil Engineering, Tokyo University of Science, 2641, Yamazaki, Noda 278-8510, Japan. \\ ii) Professor, ditto. \\ iii) Former Undergraduate Student, ditto. \\ iv) Researcher, Nippon Steel \& Sumitomo Metal Corporation, 20-1, Shintomi, Futtsu 293-8511, Japan.
}

\begin{abstract}
The coastal areas of the Pacific Ocean suffered extensive damage by the tsunami of the 2011 off the Pacific Coast of Tohoku Earthquake. Since then, it was necessary to develop reinforcement methods to strengthen the existing breakwaters against tsunamis. Therefore, the authors proposed a method to reinforce a breakwater against tsunami by backfilling the space between the breakwater and installed steel pipe piles. A series of model experiments was conducted. In the experiment, the embedment length and space between the piles were selected as parameters to improve the horizontal resistance of the caisson. A horizontal loading experiment was conducted to study the horizontal resistance of the model caisson. The model ground was prepared by dry silica sand \#5 under $80 \%$ of relative density. Strain gauges were attached to the steel piles to measure the bending moment of the piles along the pile length. The experimental results suggest that the horizontal resistance of the caisson remained stable under a certain embedded length of the piles, and the horizontal resistance of the caisson decreases when the space between the piles is long although the flexural rigidity per unit horizontal length was constant.
\end{abstract}

Keyword: tsunami, breakwater, reinforcement, steel pile, resistant behavior of ground

\section{INTRODUCTION}

The coastal areas of the Pacific Ocean suffered extensive damage by the tsunami of the 2011 off the Pacific Coast of Tohoku Earthquake, particularly many breakwaters, which are designed to keep the port facilities safe, were heavily damaged (Sugano et. al., 2014). Since then, a review of the structural design methods has been recommended. Moreover, it has been predicted with a high probability that the Tonankai, Nankai Trough earthquake might occur in near future. Therefore, the port structures are in a high demand to being strengthened against large tsunamis by reinforcing the existing caisson breakwaters more than ever. Therefore, persistently resistant breakwater against tsunami is necessary to reduce damage by large tsunamis.

Moriyasu et al. (2013) proposed a method to reinforce a breakwater by installing steel pipe piles behind the breakwater and then filling the space between them by aggregates as shown in Fig. 1. Past studies have shown that the previous gravity type breakwater can be strengthened by the reinforced method (Moriyasu et al., 2013; Oikawa et al., 2014).

For determining the design method of the steel piles, it was required to conduct experiments with changing the horizontal section and embedded length of the piles.
Therefore, the experiments were conducted by changing the embedded length of the steel piles, or the space between the piles or flexural rigidity of the piles to study the horizontal resistance of the caisson.

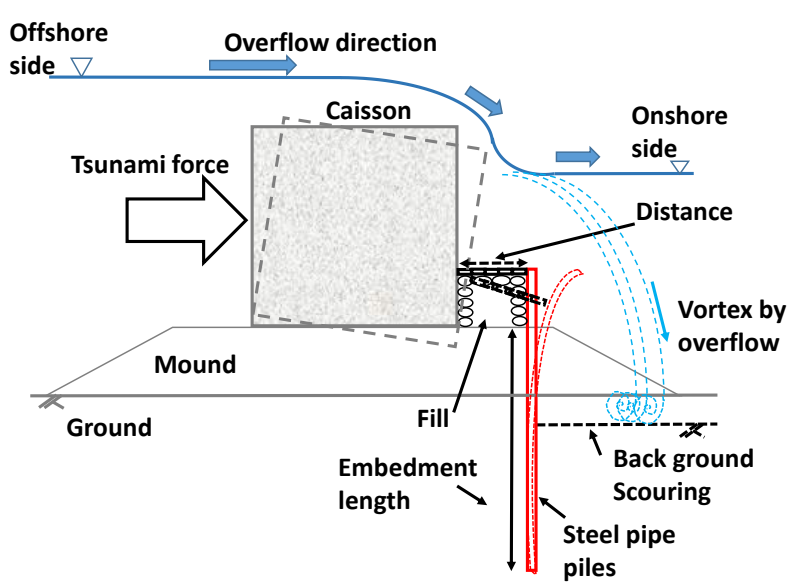

Fig. 1. Schematic diagram of a reinforced gravity type breakwater (modified after Moriyasu et al., 2013). 


\section{EXPERIMENT OUTLINE}

The experiment model was designed at 1/60 scale. This schematic diagram of the model set up is shown in Fig. 2. A steel sand box of $1580 \mathrm{~mm}$ long, $800 \mathrm{~mm}$ high and $400 \mathrm{~mm}$ wide was used to prepare the model ground as shown in Fig. 2. Dry silica sand \#5 (of $D_{50}=0.591$ $\left.\mathrm{mm}, G_{\mathrm{s}}=2.647, e_{\max }=1.072, e_{\min }=0.689\right)$ was used to prepare the model ground. The model ground was prepared with $80 \%$ of relative density by the air pluviation method. The thickness of the model ground was $450 \mathrm{~mm}$. The model caisson was $380 \mathrm{~mm}$ long, 300 $\mathrm{mm}$ high and $300 \mathrm{~mm}$ wide. Its weight was controlled at $752 \mathrm{~N}$ (i.e., $\gamma_{\mathrm{t}}=22 \mathrm{kN} / \mathrm{m}^{3}$ ). Average contact pressure to the ground was $6.6 \mathrm{kN} / \mathrm{m}^{2}$. The steel piles are $430 \mathrm{~mm}$ long and $30 \mathrm{~mm}$ wide with three different thickness to adjust $E I$ as a constant or variable as given in Table 1 .

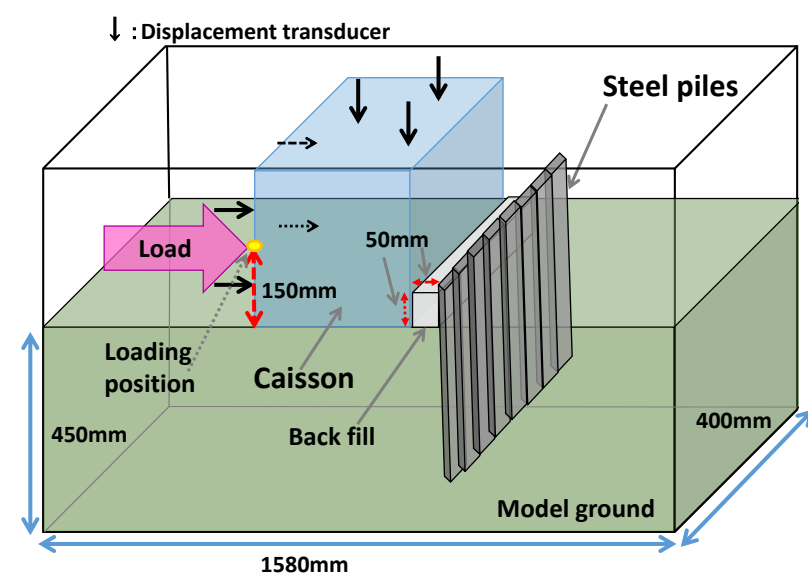

Fig. 2. Schematic diagram of the experimental model set up.

Table 1 gives the experiment cases. Schematic diagram of the model set up which view from the rear of the caisson is shown in Fig.3. Twelve steel piles of 430 $\mathrm{mm}$ long, $30 \mathrm{~mm}$ wide and $3.2 \mathrm{~mm}$ thick were embedded to change the embedment length. Four different embedment lengths were used as given in Table 1. The space between the piles were set at $3 \mathrm{~mm}$.

In the experiment of the variable pile space and flexural rigidity, the embedment length was set at 280 $\mathrm{mm}$ with 5 different patterns of various spaces and flexural rigidities. A non-reinforced case (i.e., without any piles) was also conducted to compare the result. In the experiment used, the distance between the steel piles and the caisson was set to $50 \mathrm{~mm}$. Aggregates are filled up to a $50 \mathrm{~mm}$ height between the piles and the caisson. Fine gravels were used as the aggregates here. Horizontal load was applied by a jack as shown in Fig. 2. Strain gauges were attached to the steel piles to measure the bending moment of the piles. Horizontal displacement of the center of the caisson was measured using LVDTs, fixed at 4 points on the load surface and 3 points on the upper surface (see Fig. 2). Horizontal displacements of the steel piles were measured using a laser displacement gauge, fixed at 2 points at different heights. The horizontal load was applied to the caisson at $150 \mathrm{~mm}$ height from the bottom of the caisson. Load and displacement of the jack were measured during the loading. The loading was applied under the displacement controlled condition with a loading rate of $1.0 \mathrm{~mm} / \mathrm{min}$.

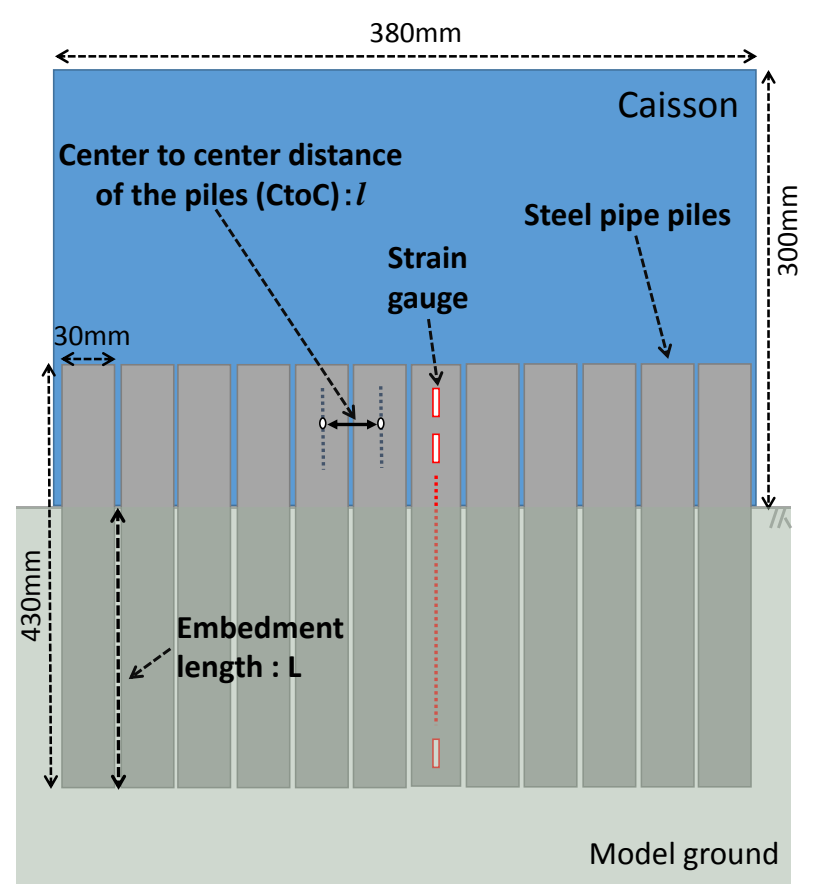

Fig.3. Schematic diagram of the experimental model set up. (The view from the rear of the caisson.)

Table 1.The details of test conditions

\begin{tabular}{|c|c|c|c|c|c|}
\hline $\begin{array}{c}\text { Test } \\
\text { notation }\end{array}$ & $\begin{array}{l}\text { Total flexural } \\
\text { rigidity, EI } \\
\left(\mathrm{kNm}^{2}\right)\end{array}$ & $\begin{array}{c}\text { Number of } \\
\text { piles }\end{array}$ & $\begin{array}{l}\text { Center to } \\
\text { center } \\
\text { distance } \\
\text { of piles } \\
l(\mathrm{~mm})\end{array}$ & $\begin{array}{l}\text { Embedded } \\
\text { length of } \\
\text { pile } \\
\mathrm{L}(\mathrm{mm})\end{array}$ & Remarks \\
\hline NPile & - & - & - & - & No pile used \\
\hline L180 & \multirow{7}{*}{0.20} & \multirow{5}{*}{12} & \multirow{5}{*}{33} & 180 & \multirow{4}{*}{$\begin{array}{c}\text { Effect of } \\
\text { embedded } \\
\text { length of piles }\end{array}$} \\
\hline L230 & & & & 230 & \\
\hline L280* & & & & 280 & \\
\hline L330 & & & & 330 & \\
\hline $\mathrm{EI} \times 12 *$ & & & & \multirow{5}{*}{280} & \multirow{5}{*}{$\begin{array}{c}\text { Effect of } \\
\text { distance } \\
\text { between piles } \\
\text { and total } \\
\text { flexural rigidity }\end{array}$} \\
\hline 2EIX6 & & 6 & 60 & & \\
\hline $4 \mathrm{EI} \times 3$ & & 3 & 120 & & \\
\hline EIX6 & 0.10 & 6 & 60 & & \\
\hline EIX3 & 0.05 & 3 & 120 & & \\
\hline
\end{tabular}

* Cases L280 and EIX12 were the same experiment. 


\section{EXPERIMENTAL RESULTS}

\subsection{Effect of embedment length}

Figure 4 shows the relationship between horizontal load and displacement at the center of the caisson when changing the embedment length of the steel piles. It indicates that a large horizontal resistance was provided by the steel piles regardless of the embedment length.

The relationships of load and displacement are more or less the same until a load of $600 \mathrm{~N}$ regardless of the embedment length. Fig. 4 also shows that the loading rate reduces in L180 case compared to the other cases. L280 and L330 cases exhibit a similar behavior until the horizontal displacement of $60 \mathrm{~mm}$.

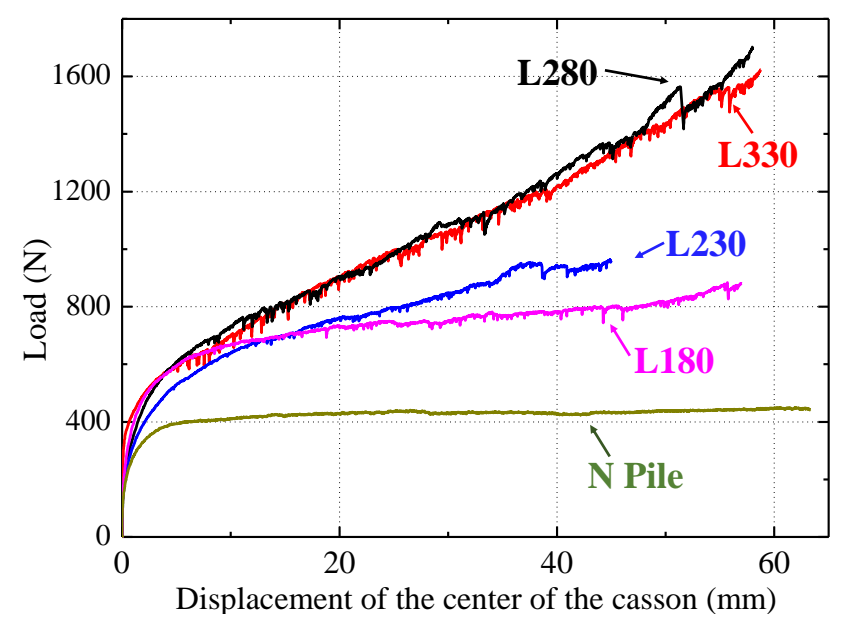

Fig. 4. Relationships between load and the displacement of the center of the caisson when changed embedment length of the steel piles.

Fig. 5 shows the bending moment distributions of L180, L230, L280 and L330 cases when the horizontal load was maintained at $750 \mathrm{~N}$. In L180 and L230 cases, where the embedment length is small, the maximum bending moment is small. Fig. 5 also shows that the maximum bending moment of L280 and L330 cases are larger than other cases. And even in L330 case, the embedded length of the pile was not sufficient for full fix condition of the pile tip, because zero bending moment point should exist if the pile can be considered as an infinitively long pile.

Fig. 6 shows the displacement of L180, L230, L280 and L330 cases when horizontal load was maintained at 750 N. Fig. 6 also indicates that L180 and L230 cases produce larger deflections than the other two cases, which should be attributed to insufficient embedded lengths. Fig. 6 also shows that L280 and L330 cases produce small and similar displacements compared to the other two cases. The smaller deflection of L280 and L330 should be due to sufficient embedded lengths. However, neither of these two cases was under stable condition.

Under this condition, the horizontal displacements at the bottom of the caisson near the steel piles were 22.3, 16.5, 8.4, $10.6 \mathrm{~mm}$ for L180, L230, L280 and L330 cases respectively. Fig. 6 also indicates that the horizontal displacements at the bottom of the steel piles were 19.3, 12.4, 5.7 and $6.8 \mathrm{~mm}$ respectively. This depicts that the relative distance between the piles and caisson decreased with the horizontal load.

Therefore, steel piles tended to overturn with insufficient length of embedment, which would be short of horizontal resistance of the caisson. On the other side, we could understand that the embedment length of the pile should not be long enough to be considered as infinitively long pile.

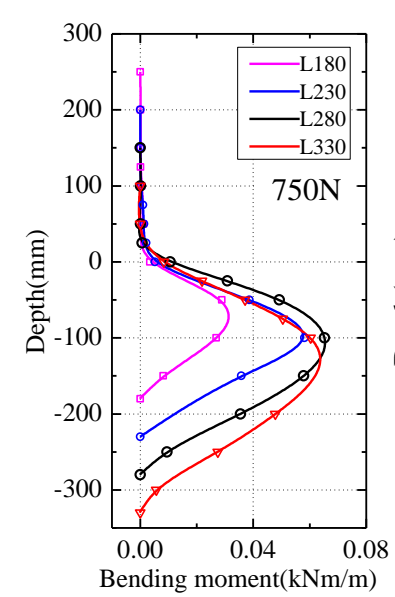

Fig. 5. Bending moment (Horizontal load of $750 \mathrm{~N}$ )

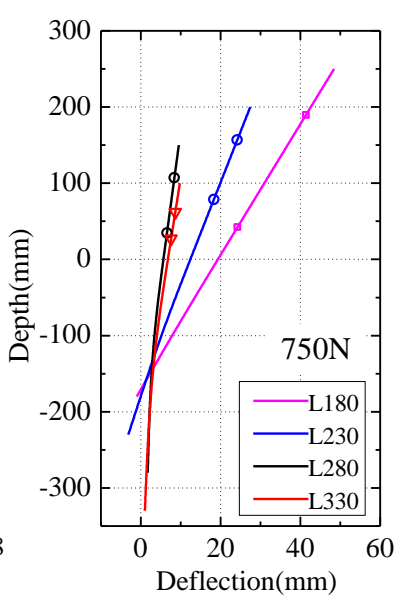

Fig. 6. Deflection (Horizontal load of $950 \mathrm{~N})$

\subsection{Effect of the difference of steel pile interval and steel pile flexural rigidity.}

Figs. 7 and 8 show the relationship between horizontal load and displacement at the center of the caisson when changing the space between the piles.

Fig. 7 shows the result when comparing the cases that the combined total flexural rigidity per unit horizontal length of the steel pile was the same. The flexural rigidity per one of the steel pile used in each experiment was different. In this experiment, flexural rigidity of a single pile in each case are $0.0168,0.0328,0.0680 \mathrm{kNm}^{2}$ for $\mathrm{EI} \times 12,2 \mathrm{EI} \times 6,4 \mathrm{EI} \times 3$ cases respectively. From Fig.7, even if the flexural rigidity per unit horizontal length of the steel piles was the same, spreading the pile interval made the resistance of the caisson lowered, and it became easier to displace the caisson. 


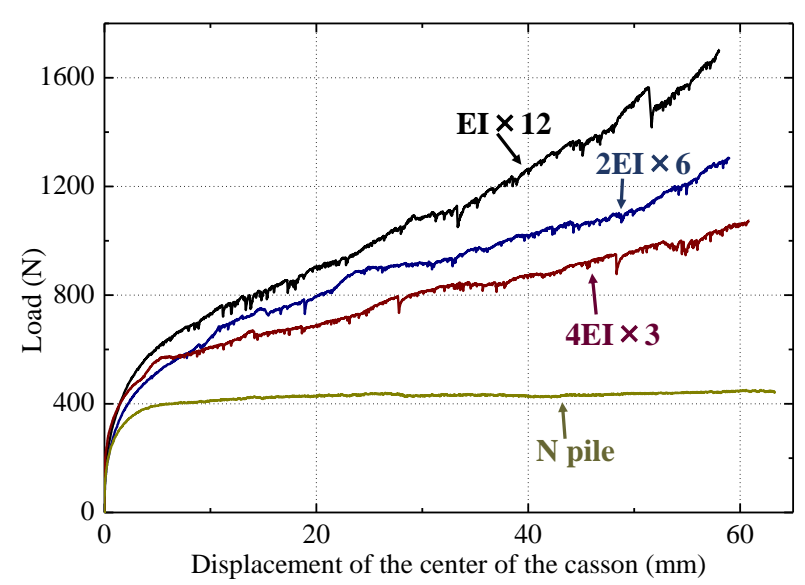

Fig. 7. Relationships of load and the displacement at the center of the caisson under various number of the steel piles and a constant rigidity/width of the steel piles.

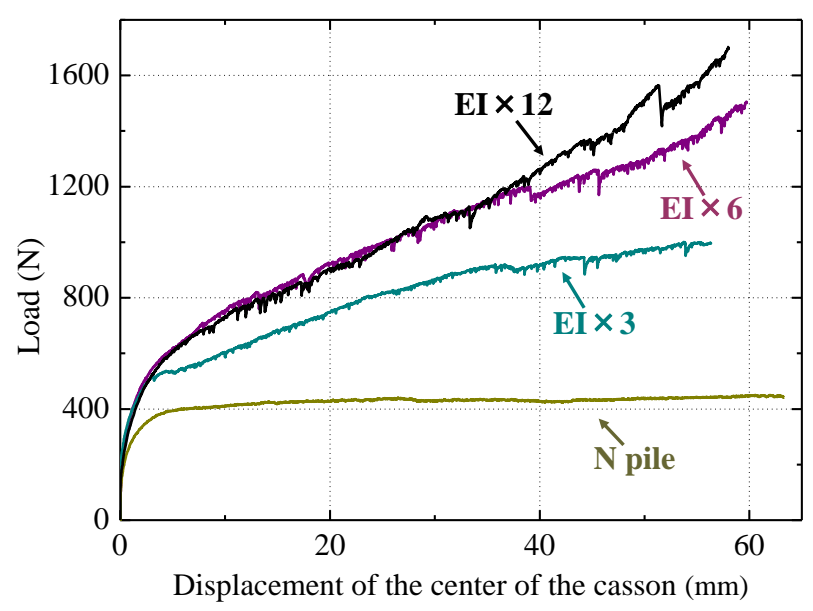

Fig. 8. Relationship of load and the displacement at the center of the caisson under various number of the steel piles.

Fig. 8 shows experimental result when reducing the number of steel piles without changing the flexural rigidity of one steel pile. From Fig.8, resistance of the caisson was found to be reduced by reducing the number of steel piles. Then, it was found that the caisson was easily displaced with reducing the number of piles.

These experimental results, by spacing the steel piles, resistance performance as viewed from the horizontal displacement behavior of the caisson was found to decrease.

Figs. 9 and 10 show the depth distribution of the bending moment and deflection of steel piles in each case at the time of the same flexural rigidity per unit horizontal length of the steel piles at $950 \mathrm{~N}$.

From Fig.9, when the number of steel piles had been reduced, since the load acting on one per steel piles increased, it can be seen that the maximum bending moment value was increased.

From Fig.10, decreased the number of the steel piles, and a large load to one per steel pile came to action, tipping behavior of the steel pile became remarkable, the vicinity of the lower end of the steel pile was displaced in the caisson side. This is because the rigidity of the steel pile is high, embedment length of relatively piles was due to become insufficient. Further, since the load per one steel piles increased, it was due to the embedment length of a steel pile was relatively short.

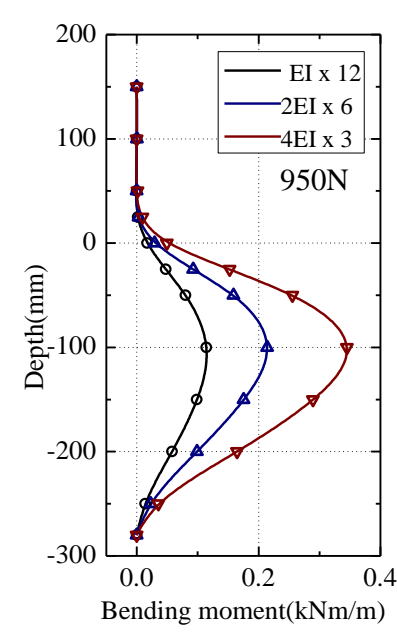

Fig. 9. Bending moment (Horizontal load of $950 \mathrm{~N}$ )

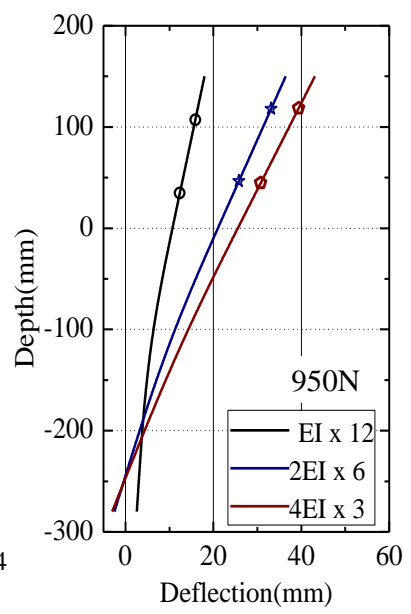

Fig. 10. Deflection (Horizontal load of $950 \mathrm{~N})$
Fig.11 and Fig.12 show the depth distribution of the deflection and bending moment of the steel piles in each case when changing the number of the steel piles with the steel pile with the same flexural rigidity.

From Fig.11, similarly to the Fig.9, when the steel pile number was reduced, the maximum bending moment value increased.

From Fig.12, when a reduced number of steel piles without changing the flexural rigidity of the steel pile, the steel piles deformed to bend greater. This is because that the maximum bending moment was increased by the load acting on one per steel piles increased. In this case, the effect due to the embedment length of a steel pile was relatively shortened.

When comparing the case of EI $\times 3$ and $4 \mathrm{EI} \times 3$, where the load acting on a steel pile was almost the same level, a big difference occurs in the bending way of the steel piles, since the flexural rigidities of the steel piles were significantly different. As a result, although the amount of deflections at the ground surface of the steel piles in case EI $\times 3$ and $4 \mathrm{EI} \times 3$ were also substantially equal, it should be noted that the behaviors of the steel piles were different. 


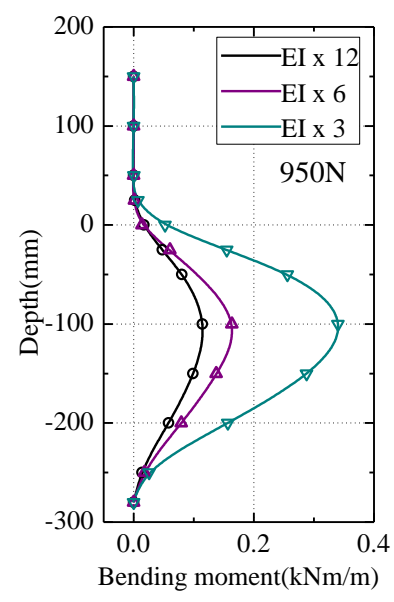

Fig. 11. Bending moment (Horizontal load of 950 N)

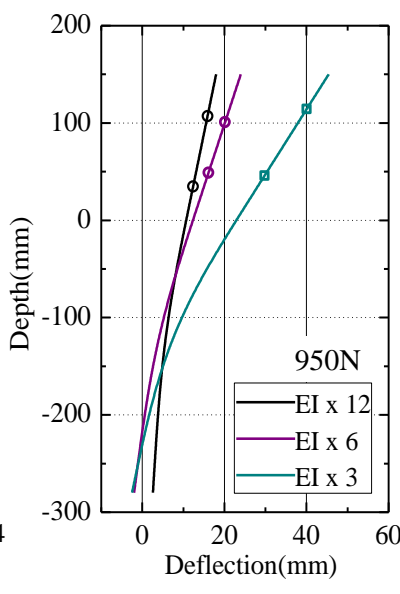

Fig. 12. Deflection (Horizontal load of $950 \mathrm{~N})$

\section{CONCLUSIONS}

In this paper, the model horizontal loading test results of the reinforcement method by steel piles of the breakwater that assumes the tsunami measures were described. From the result, reinforcing effect of this method was very large, it found that there is sufficient practicality.

From the research, the effects of the difference of embedment length of steel piles and interval and rigidity of the steel piles to the reinforcement of the breakwater were summarized as follows:

(1) Effect of the embedment length of steel piles

By changing the embedment length of steel piles, the behavior of the steel pile was changed and the resistance behavior of the caisson was changed. However, in case that the embedment length of the pile was not too short such as the length was sufficiently long to be considered as flexural pile, the reinforced resistance of the caisson was not affected by the embedded length of piles.

Required embedded length of the pile can be changed according to the load considered to resist the caisson. The embedded length for performing flexural pile is changed according to the load level to the pile. As shown in the experimental results in Fig. 4, even in case L180, there were no difference in resistant behavior of caisson in other cases as L230, L280, and L330 at the load level of $600 \mathrm{~N}$. It means at the load level of $600 \mathrm{~N}$ even in L180 the pile behaved as flexural pile.

(2)Effect of the differences of steel pile interval and steel pile flexural rigidity

The differences of steel pile interval and steel pile flexural rigidity affect the resistance of the caisson. Even if the flexural rigidity per unit horizontal length of the steel piles was the same, spreading the pile interval made the resistance of the caisson lowered, and it became easier to displace the caisson. Reducing the number of steel piles without changing the flexural rigidity of one steel pile made the resistance of the caisson reduced. Only looking at the displacement of the caisson, there were small differences in the difference of flexural rigidity of a pile. But the deformation behavior of a pile was different with different flexural rigidity of a pile.

\section{ACKNOWLEDGEMENTS}

The authors acknowledge Mr. Tanaka, Mr. Oikawa, and Dr. Taenaka, Nippon Steel Sumitomo Metal Corporation, Japan for their supports in conducting the experiments and analysis.

\section{REFFERENCES}

1) Moriyasu, S., Tanaka, R., Oikawa, S., Miyamoto, T., Yoshiwara, K., Kikuchi, Y., Kawabe, S. and Mizuno, R., (2013): Efforts to achieve a tough structure of tsunami measures breakwater that utilizes steel wall, 7th Nankai earthquake Shikoku region Academic Symposium (in Japanese).

2) Oikawa, S., Kikuchi, Y., Kawabe, S., Mizuno, R., Moriyasu, S., Tanaka, R. and Taenaka, S. (2014): An experimental study for reinforcing construction of breakwater with structural steel, Proceedings of Special Symposium of Japanese Geotechnical Society on Through the Great East Japan Earthquake, 67(4), 703-709 (in Japanese).

3) Sugano, T., Nozu, A., Kohama, E., Shimosako, K., and Kikuchi, Y., (2014): Damage to coastal structures, Soils and Foundations, 54(4), 883-901. 